\title{
Research on the development and competitiveness evaluation of manufacturing industry in Yangtze River Economic Belt
}

\author{
Zongguang Wang ${ }^{1}$, Yamin Jiang ${ }^{1}$ * \\ ${ }^{1}$ Lanzhou University of Technology, School of economics and management, Lanzhou, Chian
}

\begin{abstract}
To promote the high-quality development of the Yangtze River economic belt is a major development strategy in China. As the lifeblood of the national economy, manufacturing industry is of great significance to realize the high-quality development of the Yangtze River economic belt. Based on the analysis of the overall situation of the manufacturing industry in the Yangtze River economic belt and the diamond model theory, this paper constructs an evaluation index system of manufacturing industry competitiveness with 4 first-class indexes and 16 second-class indexes, comprehensively evaluates the manufacturing industry competitiveness of each region by entropy method, and ranks the whole country. The results show that the manufacturing competitiveness of 11 provinces and cities in the Yangtze River economic belt is quite different and has obvious regional characteristics. The competitiveness of manufacturing industry in downstream regions is strong, while that in Yunnan and Guizhou provinces is weak, ranking at the bottom. Through indepth analysis, it is found that there are some problems, such as unbalanced development, homogenization of industry, unreasonable layout of manufacturing industry. Combined with the development experience of excellent manufacturing industry and the regional characteristics of the Yangtze River economic belt, this paper proposes that we should speed up the industrial agglomeration, adhere to the innovation driven strategy, optimize the industrial layout and other ways to enhance the manufacturing competitiveness of the Yangtze River economic belt and promote the high-quality development of the Yangtze River economic belt.
\end{abstract}

\section{Introduction}

On April 26, 2018, forum on promoting the development of Yangtze River Economic Belt held in Wuhan, general secretary $\mathrm{Xi}$ Jinping stressed that Promoting the development of the Yangtze River economic belt is a major decision made by the Party Central Committee and a major strategy related to the overall development of the country. On November 14, 2020, general secretary Xi Jinping held a forum to promote the development of the Yangtze River Economic Belt in Nanjing. He stressed that we must unswervingly implement the new development concept, promote the high quality development of the Yangtze River economic belt, and build the Yangtze River economic belt into a new force in the development of China's economy. As the foundation of a powerful country, manufacturing industry is an important field to promote the high-quality development of the Yangtze River economic belt. The Yangtze River economic belt has obvious regional advantages, resource advantages and industrial advantages. Although its economic development level has been ahead of the national level, there are still many problems. How to improve the development level of manufacturing industry in the Yangtze River economic belt is of great significance to promote the high-quality development of the Yangtze River economic belt and improve the level of China's manufacturing industry.
In the information age, manufacturing industry not only provides necessary means of production for agriculture, construction, service industry, but also provides product and technical support for high-end manufacturing, financial, logistics industry, and has a strong driving role for other industries ${ }^{[1]}$. Manufacturing innovation makes the proportion between industries and the proportion of internal structure change, which promotes industrial upgrading and high-quality economic development.

With the rise of a new round of scientific and technological revolution and industrial revolution, the transformation and upgrading of manufacturing industry has become a new trend of the world economic development. Western countries have put forward corresponding plans for the transformation and upgrading of manufacturing industry. The United States has put forward the strategy of reindustrialization to revive the economy. Germany has put forward the strategy of Industry 4.0 and Japan has formulated white paper on Japanese manufacturing. The phenomenon that China's manufacturing industry is large but not strong is very obvious. The environmental constraints and the weak ability of independent innovation have become the main bottlenecks in the development of China's manufacturing industry ${ }^{[2]}$. In the 12th Five Year Plan, China puts forward the strategic goal of transformation and upgrading of manufacturing industry and improvement of industrial 
core competitiveness ${ }^{[3]}$. In 2015, made in China 2025 was proposed to accelerate the transformation from a big manufacturing country to a powerful manufacturing country. The transformation and upgrading of manufacturing industry promotes the development of regional economy, so as to promote the high-quality development of Chinese economy.

In the post industrialization stage, the industrial structure of the United States goes from the real to the virtual, the manufacturing industry is shrinking, the industry hollowing is serious, and the imbalance between virtual economy and real economy, causing the US economic bubble and financial crisis. The softening of Japanese industrial structure and the localization of industrial capital are the important reasons for the hollow industry [4]. Manufacturing industry is the key to the healthy development of a country's economy. The status of manufacturing industry can effectively reduce the phenomenon of industry hollowing out.

\section{Analysis on the overall situation of manufacturing industry in the Yangtze River Economic Belt}

\subsection{Economic aggregate of Yangtze River Economic Belt}

This paper selects the data of 2019. The total economic volume (V1) of the Yangtze River economic belt is 457.805 billion, accounting for $46.20 \%$ of the whole country. It can be seen from table 1 that the total economic volume of 11 provinces and cities along the Yangtze River Economic Belt varies greatly. The total economic volume of Jiangsu reaches 9963.152 billion, accounting for $21.76 \%$ of the total economic volume of the Yangtze River economic belt, with the highest proportion. However, Guizhou accounts for $3.66 \%$ of the total economic volume of the Yangtze River economic belt, with the lowest proportion. In terms of export (V2), Guizhou has the lowest export volume, and Jiangsu Province's export volume is 83 times that of Guizhou. From the growth rate of industrial added value (V3), Jiangxi, Hunan, Guizhou, Yunnan and other regions grew faster. From the total retail sales of social consumer goods (V4), Jiangsu is the highest, followed by Hubei, and Guizhou is the lowest.

\subsection{Scale of manufacturing industry in Yangtze River Economic Belt}

Table1. Main economic indicators of China and the Yangtze River Economic Belt in 2019 Unit: 100 million \%

\begin{tabular}{lcccccccccccc}
\hline \multicolumn{6}{c}{ countrywide } & Shanghai Jiangsu & Zhejiang & Anhui & Jiangxi & Hubei & Hunan & Chongqing Sichuan Guizhou Yunnan \\
\hline V1 & 990865 & 38155.32 & 99631.5 & 62352 & 37114 & 24757.5 & 45828.31 & 39752.1 & 23605.77 & 46615.8 & 16769.3 & 23223.75 \\
V2 & 5.7 & 0.4 & 6.2 & 6.6 & 7.3 & 8.4 & 7.8 & 8.3 & 6.4 & 7.9 & 9.6 & 8.1 \\
V3 & 172342 & 13720.91 & 27208.6 & 23070 & 2785.4 & 2496.5 & 2484.9 & 3076.1 & 3712.92 & 3892.3 & 327.14 & 1036 \\
V4 & 5.1 & 5.1 & 5.1 & 10.1 & 9.2 & 9.2 & 10.6 & 10.1 & 5.7 & 0.102 & 1 & 8.5 \\
V5 & 411649 & 13497.21 & 35291.2 & 27176 & 13377.7 & 8421.6 & 20224.23 & 17239.5 & 8667.3 & 20144.3 & 4174.2 & 7539.18 \\
\hline
\end{tabular}

In order to describe the development of manufacturing industry in the Yangtze River Economic Belt in detail, this paper sorts out the situation of 28 major manufacturing industries. Due to most provinces and cities have not announced the added value and output value of manufacturing industry, this paper selects the total profit of manufacturing industry to sort, as shown in figure1. According to the high-tech industry (Manufacturing) classification 2017 issued by the National Bureau of statistics, high-tech industries include pharmaceutical manufacturing(L1), aviation, spacecraft and equipment manufacturing(L2), electronic and communication equipment manufacturing(L3), computer and office equipment manufacturing(L4), medical equipment and instrumentation manufacturing (L5), and information chemicals manufacturing (L6). As we can see from figure 1 , the chemical raw materials and chemical products manufacturing industry, computer, communication and other electronic equipment manufacturing industry, general equipment manufacturing industry, pharmaceutical manufacturing industry and special equipment manufacturing industry are involved in hightech industries among the top 10 industries. At the same time, it analyzes the proportion of high-tech industry production and operation in 11 provinces and cities of the Yangtze River Economic Belt in the national high-tech industry. The data comes from China high tech statistical yearbook. The data can be considered. Four types of hightech industries are selected, as shown in Table 3.

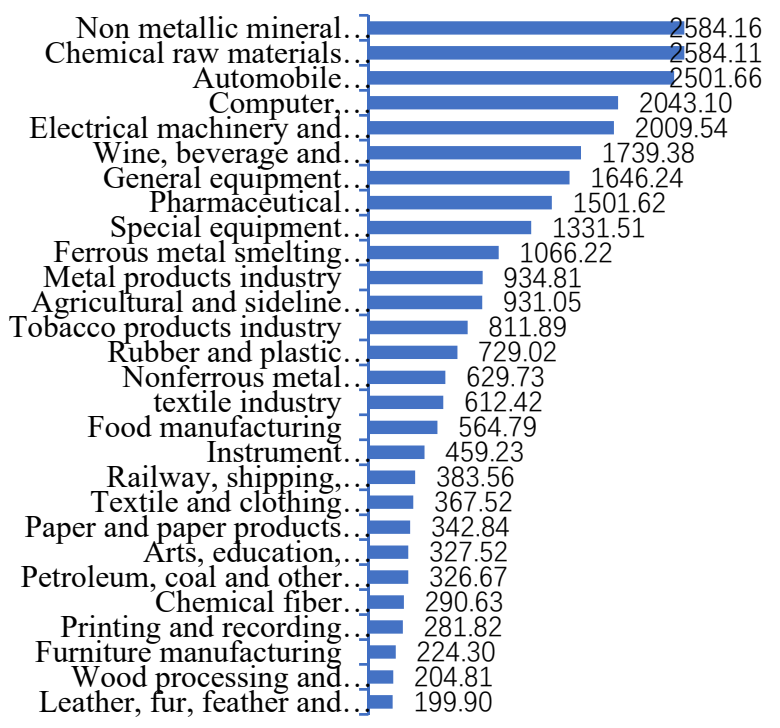

Figure 1. Total profits of major manufacturing industries in the Yangtze River Economic Belt in 2019 Unit: 100 million 
Table2. Total profits of major manufacturing industries in China and the Yangtze River Economic Belt in 2019 Unit: billion

\begin{tabular}{|c|c|c|c|c|c|c|c|c|c|c|c|c|}
\hline & countrywide & Shanghai & Jiangsu & Zhejiang & Anhui & Jiangxi & Hubei & Hunan & Chongqing & Sichuan & Guizhou & Yunnan \\
\hline $\mathrm{C} 13$ & 205.20 & 1.72 & 6.87 & 3.01 & 9.60 & 10.60 & 22.54 & 15.00 & 6.42 & 13.05 & 1.05 & 3.24 \\
\hline $\mathrm{C} 14$ & 178.91 & 7.47 & 6.49 & 5.12 & 3.32 & 3.31 & 7.59 & 8.09 & 2.29 & 9.15 & 1.30 & 2.35 \\
\hline $\mathrm{C} 15$ & 228.67 & 0.88 & 18.29 & 5.37 & 8.97 & 3.55 & 11.69 & 4.33 & 2.74 & 52.67 & 61.33 & 4.12 \\
\hline $\mathrm{C} 16$ & 93.31 & 24.12 & 9.59 & 5.26 & 0.78 & 1.07 & 10.83 & 8.51 & 0.31 & 0.81 & 2.12 & 17.78 \\
\hline $\mathrm{C} 17$ & 113.25 & 1.06 & 14.40 & 19.00 & 3.52 & 5.02 & 10.16 & 2.41 & 0.28 & 3.19 & 0.07 & 0.10 \\
\hline $\mathrm{C} 18$ & 87.76 & 0.50 & 8.04 & 10.35 & 2.91 & 6.37 & 4.62 & 1.71 & 0.31 & 1.75 & 0.17 & 0.13 \\
\hline C19 & 80.07 & 1.00 & 1.19 & 3.23 & 2.15 & 4.38 & 1.38 & 4.33 & 0.90 & 1.26 & 0.32 & 0.01 \\
\hline $\mathrm{C} 20$ & 42.71 & 0.35 & 3.23 & 3.06 & 2.53 & 2.43 & 2.07 & 2.92 & 1.55 & 1.70 & 0.28 & 0.33 \\
\hline C21 & 48.84 & 3.70 & 1.66 & 5.52 & 1.82 & 2.98 & 1.68 & 1.47 & 1.00 & 2.30 & 0.25 & 0.04 \\
\hline $\mathrm{C} 22$ & 73.23 & 1.81 & 9.04 & 7.42 & 2.22 & 2.86 & 2.56 & 3.10 & 2.33 & 2.43 & 0.50 & 0.27 \\
\hline $\mathrm{C} 23$ & 46.90 & 1.88 & 4.71 & 3.02 & 2.56 & 2.26 & 4.12 & 3.26 & 2.00 & 2.84 & 0.43 & 1.02 \\
\hline $\mathrm{C} 24$ & 76.02 & 4.94 & 6.05 & 6.94 & 2.53 & 3.82 & 2.93 & 1.92 & 1.09 & 0.63 & 0.16 & 1.47 \\
\hline $\mathrm{C} 25$ & 125.56 & 5.32 & 6.96 & 11.00 & 1.75 & 1.14 & 0.53 & 1.48 & 0.17 & 2.83 & 0.28 & 1.31 \\
\hline $\mathrm{C} 26$ & 379.75 & 34.33 & 64.49 & 63.98 & 14.12 & 15.38 & 19.62 & 16.33 & 6.30 & 19.28 & (1.97) & 4.28 \\
\hline $\mathrm{C} 27$ & 318.42 & 14.87 & 46.07 & 23.13 & 6.94 & 12.20 & 13.47 & 7.33 & 5.48 & 16.14 & 3.07 & 6.51 \\
\hline C28 & 36.26 & 0.02 & 11.04 & 12.10 & 1.06 & 0.30 & 0.07 & 0.07 & 0.46 & 0.49 & 0.00 & 0.38 \\
\hline C29 & 142.19 & 7.20 & 15.92 & 14.28 & 9.26 & 5.95 & 6.60 & 3.90 & 2.87 & 5.39 & 1.02 & 0.52 \\
\hline C30 & 488.78 & 4.79 & 28.18 & 27.85 & 40.07 & 29.87 & 32.22 & 23.99 & 16.91 & 36.96 & 6.16 & 11.43 \\
\hline C31 & 285.24 & 8.29 & 40.05 & 6.72 & 6.68 & 10.62 & 9.37 & 9.82 & 3.68 & 6.95 & 0.96 & 3.48 \\
\hline C32 & 158.10 & 1.28 & 12.42 & 4.64 & 3.42 & 20.28 & 1.72 & 4.92 & 3.06 & 3.62 & 2.22 & 5.38 \\
\hline C33 & 178.60 & 5.21 & 28.34 & 14.64 & 6.54 & 5.81 & 8.86 & 9.68 & 4.51 & 8.09 & 1.33 & 0.46 \\
\hline C34 & 264.90 & 22.05 & 55.12 & 36.73 & 10.76 & 6.19 & 7.08 & 9.01 & 7.77 & 9.37 & 0.57 & $(0.01)$ \\
\hline C35 & 232.37 & 13.96 & 42.81 & 16.49 & 7.30 & 3.97 & 7.34 & 28.69 & 4.36 & 7.57 & 0.33 & 0.33 \\
\hline C36 & 509.99 & 79.53 & 44.02 & 45.28 & 5.83 & 2.84 & 57.06 & 1.24 & 2.53 & 11.49 & 0.35 & $(0.00)$ \\
\hline C37 & 79.17 & 2.89 & 16.89 & 0.54 & 0.44 & 0.61 & 0.36 & 4.89 & 6.32 & 4.47 & 0.82 & 0.13 \\
\hline C38 & 394.34 & 15.01 & 63.53 & 46.52 & 22.67 & 15.68 & 12.31 & 8.66 & 7.71 & 7.60 & 0.86 & 0.40 \\
\hline C39 & 537.36 & 17.71 & 60.09 & 39.25 & 11.60 & 16.71 & 8.25 & 14.47 & 13.55 & 14.01 & 1.69 & 7.00 \\
\hline $\mathrm{C} 40$ & 75.48 & 5.29 & 14.09 & 15.78 & 1.43 & 1.23 & 1.74 & 1.96 & 1.46 & 2.24 & 0.09 & 0.60 \\
\hline
\end{tabular}

Table3. Proportion of high tech industries in the Yangtze River Economic Belt in the whole country Unit \%

\begin{tabular}{lllll}
\hline Region & L1 & L3 & L4 & L5 \\
\hline Shanghai & 4.67 & 3.35 & 1.68 & 8.27 \\
Jiangsu & 14.47 & 11.12 & 17.36 & 19.52 \\
Zhejiang & 7.26 & 7.49 & 2.77 & 15.99 \\
Anhui & 2.18 & 1.94 & 3.27 & 1.93 \\
Jiangxi & 3.89 & 3.75 & 2.36 & 1.82 \\
Hubei & 4.23 & 1.95 & 1.81 & 1.91 \\
Hunan & 2.30 & 2.88 & 1.27 & 2.70 \\
Chongqing & 1.72 & 1.38 & 10.56 & 1.59 \\
Sichuan & 5.07 & 2.12 & 5.00 & 2.62 \\
Yunnan & 2.04 & 1.32 & 0.15 & 0.16 \\
Guizhou & 0.97 & 0.34 & 0.15 & 0.09 \\
\hline
\end{tabular}

\section{The construction and result analysis of the index system of manufacturing industry development competitiveness in the Yangtze River Economic Belt}

\subsection{The construction of competitiveness index}

As for the research of industrial competitiveness, foreign countries focus on the influencing factors of industrial competitiveness at the national level, while domestic researches mainly focus on the evaluation system, research methods and empirical research of regional industrial competitiveness. Previous studies provide us with a good research perspective. Based on Porter's Diamond Model, combined with the actual situation of China and the trend of high-quality development, this paper constructs an index system including 4 first level indicators and 16 second level indicators, including input factors, output factors, knowledge and innovation factors and environment factors (Table 2). Knowledge and innovation elements, as an important factor, are also the key to improve the competitiveness and high-quality development of manufacturing industry.

\subsection{Sample data source and method selection}

The data in this paper come from China Industrial statistical yearbook, China Statistical Yearbook, China high tech industry statistical yearbook and China Science and Technology Yearbook in 2020.The entropy method is used to process the data. Entropy method is an objective weighting method, which can avoid the subjectivity of index selection by calculating the weight through the internal relationship of the original data index. Its principle is to measure the effective information of the known index data through the entropy value and further calculate the weight, that is, to determine the weight of each index through the index difference degree of the evaluation object. If the entropy value is small, it indicates that the greater the amount of information contained in the index, the more effective information it can provide, and the greater the role it plays in the comprehensive evaluation, the greater the weight is, and vice versa ${ }^{[5]}$. The specific calculation steps of entropy method: First, data standardization. In order to eliminate the difference of dimension and order of magnitude of different indexes, range transformation is used to standardize the data. Second, calculate the index weight of the $j$ index on the $i$ evaluation object. Third, calculate the entropy of the $j$-th 
index. Fourth, calculate the difference coefficient of index. Fifth, calculate the weight of index $J$. Sixth, comprehensive evaluation of the competitiveness of the $i$ region.

$$
\begin{aligned}
& \text { Positive indicators } x_{i j}^{*}=\frac{x_{i j-x_{j}^{\min }}}{x_{j}^{\text {max }}-x_{j}^{\text {min }}}+0.0001 \\
& \text { Reverse index } x_{i j}^{*}=\frac{x_{j}^{\text {min }}-x_{i j}}{x_{j}^{\text {max }}-x_{j}^{\text {min }}}+0.0001 \\
& p_{i j}=\frac{x_{i j}^{*}}{\sum_{i=1}^{n} x_{i j}^{*}} \\
& e_{j}=-k \sum_{i=1}^{n} p_{i j} \ln \left(p_{i j}\right), \mathrm{k}=1 / \ln (\mathrm{n}), n=31 \\
& d_{j}=1-e_{j} \\
& W_{J}=\frac{d_{j}}{\sum_{j=1}^{n} d_{j}} \\
& F_{i}=\sum W_{j} x_{i j}
\end{aligned}
$$

\subsection{Analysis of the results of the measurement of manufacturing competitiveness}

\subsubsection{Index weight}

Using entropy method to calculate the weight of each index of 31 provinces and cities in China in 2019

(Table 4). Summing up the secondary indexes, it is concluded that knowledge and innovation elements

Table4. Competitiveness index system of manufacturing industry in Yangtze River Economic Belt

\begin{tabular}{c|c|c|c|c|c|c}
\hline $\begin{array}{c}\text { First level } \\
\text { indicators }\end{array}$ & Secondary indicators & $\begin{array}{c}\text { categor } \\
\mathrm{y}\end{array}$ & number & Entropy & $\begin{array}{c}\text { Coefficient } \\
\text { of } \\
\text { difference }\end{array}$ & weight \\
\hline \multirow{2}{*}{$\begin{array}{c}\text { productio } \\
\text { n factors }\end{array}$} & $\begin{array}{c}\text { Operating cost of manufacturing industry } \\
\text { Average number of employees in manufacturing } \\
\text { industry }\end{array}$ & - & $\mathrm{x} 1$ & 0.9809 & 0.0191 & 0.0080 \\
& Net fixed assets & + & $\mathrm{x} 2$ & 0.8324 & 0.1676 & 0.0704 \\
& Expenditure on high tech transformation & + & $\mathrm{x} 3$ & 0.9074 & 0.0926 & 0.0389 \\
Output & Total profit & + & $\mathrm{x} 5$ & 0.6703 & 0.3297 & 0.1385 \\
factors & Operating income of manufacturing industry & + & $\mathrm{x} 6$ & 0.9195 & 0.0805 & 0.0338 \\
& The industrial added value is & + & $\mathrm{x} 7$ & 0.8855 & 0.1305 & 0.0548 \\
\hline Knowledg & Sales revenue of new products & + & $\mathrm{x} 8$ & 0.7980 & 0.1145 & 0.0481 \\
e and & General colleges and Universities & + & $\mathrm{x} 9$ & 0.9515 & 0.0485 & 0.020 \\
innovatio & Number of valid invention patents & + & $\mathrm{x} 10$ & 0.7485 & 0.2515 & 0.1056 \\
$\mathrm{n}$ & Number of R \& D projects & + & $\mathrm{x} 11$ & 0.7806 & 0.2194 & 0.0921 \\
elements & R \& D personnel in high tech industry & + & $\mathrm{x} 12$ & 0.7368 & 0.2632 & 0.1105 \\
\hline External & Freight volume & + & $\mathrm{x} 13$ & 0.9246 & 0.0754 & 0.0317 \\
environm & Local general public budget revenue & + & $\mathrm{x} 14$ & 0.8972 & 0.1028 & 0.0432 \\
ental & Internal expenditure of R\&D expenditure & + & $\mathrm{x} 15$ & 0.8425 & 0.1575 & 0.0662 \\
factors & Per capita disposable income & + & $\mathrm{x} 16$ & 0.8734 & 0.1266 & 0.0532 \\
\hline
\end{tabular}

\subsection{3 comprehensive analysis}

As mentioned above, in the competitiveness index system of manufacturing industry in the Yangtze River economic belt, high-tech transformation expenditure, number of effective invention patents, R \&amp; D personnel of hightech industry and other indicators account for a large proportion. It can be seen that innovation is a key factor to improve the competitiveness of manufacturing industry. According to table 4 and Figure 2, the competitiveness of manufacturing industry is closely related to high-tech industries. Among these four types of high-tech industries, account for $32.9 \%$, of which the number of effective invention patents and R\&D personnel in high-tech industry account for a large proportion. The second was production factors, accounting for $25.6 \%$, of which the expenditure on high-tech transformation accounts for $13.85 \%$. From the weight of these indicators, we can see that knowledge and innovation elements have a great effect on the competitiveness of manufacturing industry.

\subsubsection{Calculation results and analysis}

According to the comprehensive evaluation model of manufacturing competitiveness, the manufacturing competitiveness ranking of 31 provinces and cities in China is calculated by entropy method (Table 4). It can be seen from the ranking that the competitiveness of manufacturing industry in the Yangtze River economic belt is ranked at the top in most regions, and six provinces and cities have entered the top 10 in China. Among them, Jiangsu Province is the strongest, ranking second in the country, followed by Zhejiang Province, ranking third in the country. However, Guizhou Province and Yunnan Province are ranked 22 and 23, which are relatively weak. 
of Yunnan Province and 9 times that of Guizhou Province. The characteristics of heavy industrialization in the Yangtze River economic belt are obvious, which is related to the initial industrial layout. At the same time, it is found that in order to catch up with the economic development, some provinces and regions have established some manufacturing industries that are not suitable for the local characteristics. The homogenization of industrial structure is serious, which not only fails to improve the development level, but also causes a waste of resources. Guizhou Province should reduce the investment in chemical raw materials and chemical products manufacturing industry or change the investment mode, and increase the investment in wine, beverage and refined tea manufacturing industry, so as to improve the competitiveness of manufacturing industry in Guizhou Province; Yunnan Province should also change the way of investment in general equipment and automobile manufacturing, and increase the manufacturing industry suitable for local development, such as tobacco products and non-ferrous metal smelting. Table 2 and table 5 show the details.

Table5. Competitiveness of manufacturing industry in 11 provinces and cities of Yangtze River economic belt and its ranking in China

\begin{tabular}{c|c|c}
\hline Region & Competitiveness index & Ranking \\
\hline Jiangsu & 0.6448 & 2 \\
Zhejiang & 0.4804 & 3 \\
Shanghai & 0.2573 & 5 \\
Anhui & 0.2323 & 7 \\
Hubei & 0.2212 & 9 \\
Sichuan & 0.2118 & 10 \\
Hunan & 0.1995 & 12 \\
Jiangxi & 0.1604 & 14 \\
Chongqing & 0.1261 & 17 \\
Yunnan & 0.0789 & 22 \\
Guizhou & 0.0713 & 23 \\
\hline
\end{tabular}

\section{Conclusion}

In order to improve the competitiveness of manufacturing industry in the Yangtze River economic region and promote high-quality economic development, all regions should attach importance to innovative elements and implement differentiated development in combination with local characteristics. First, we should take innovation driven as the driving force to promote the intelligent development of manufacturing industry. Innovation driven strategy is the core driving force for the high-quality development of China's manufacturing industry in the new era, and plays a key role in the process of high-quality development of manufacturing industry ${ }^{[6]}$. Second, we should build a differentiated industrial layout. Considering the differences of regional resource endowment, we should plan the competition and market layout of strategic emerging industries in the middle and upper reaches of the Yangtze River economic belt, and do a good job in policy guidance, so as to promote the industrial layout of relevant regions to develop in the direction of rationalization and scientization of division of labor and ensure the sustainability of their development ${ }^{[7]}$. Third, we should give better play to the role of the government, reduce the excessive interference of local governments in enterprises, eliminate unnecessary barriers, increase the innovation vitality of the market, and improve the competitiveness of enterprises, so as to promote high-quality economic development.

\section{Reference:}

1. Han Haiyan, Ren Baoping. On Economic Problems Research on the development and competitiveness evaluation of manufacturing industry in the high quality development of the Yellow River Basin [J]. 08, 1-9 (2020)

2. Li Lianshui, Cheng Zhonghua, Liu Jun. China Industrial Economics. Research on the new type of China's manufacturing industry and its evaluation [J]. 02, 63-75 (2015)

3. Zhang Qizai, Li Lei. Research on Economics and Management. Transformation and upgrading of manufacturing industry and regional economic growth [J]. 38 (02) 97-111 (2017)

4. $\mathrm{Hu}$ Lijun, Xue Fugen, Wang Yu. China Industrial Economics. The mechanism and governance of Industrial Hollowing in the post-industrial stage--a case study of Japan and the United States [J]. 08 122134 (2013)

5. Zheng Zhenyuan, Liu Jing, Li Yue. East China Economic Management .Comprehensive evaluation of marine industry in East China Sea Based on entropy method [J].33 (09)97-102 (2019)

6. Ren Baoping. The Journal of Humanities. Six strategies for high quality development of China's manufacturing industry in the new era $[\mathrm{J}] .0731$ 38(2019)

7. Luo Liangwen, Zhao Fan. Reform. Industrial layout optimization and high quality development of Yangtze River Economic Belt: Based on the perspective of interregional industrial transfer $[\mathrm{J}] .02$ 27-36(2019) 